\title{
Do Direito à Educação à Necessidade de Tecnologias Assistivas para Estudantes com Deficiência: um Estudo de Caso Sobre a Univesp
} From the Right to Education to the Need of Assistive Technologies

\author{
Lucas de Almeida Pinheiro ${ }^{1 *}$ \\ Fabiana Pedroni ${ }^{2}$ \\ Aline Michelle $\mathrm{Dib}^{3}$ \\ Leticia Trevizolli de Oliveira ${ }^{2}$ \\ Michele Carolina Silva ${ }^{1}$ \\ 1 Universidade Estadual de Campinas. \\ Cidade Universitária Zeferino Vaz - Barão \\ Geraldo, Campinas - SP - Brasil. \\ *lucasalpinheiro@gmail.com \\ 2 Universidade Estadual Paulista Júlio de \\ Mesquita Filho. Rua Quirino de Andrade, \\ 215 - Centro, São Paulo - SP - Brasil. \\ 3 Universidade de São Paulo. Butantã - \\ São Paulo - SP - Brasil.
}

\section{Resumo}

O presente artigo buscou compreender aspectos relacionados à presença de ferramentas tecnológicas e recursos de acessibilidade que promovam a inclusão no ensino superior na modalidade a distância. Partimos de estudos normativos e de diretrizes legais para a compreensão da educação como um direito. Relacionamos tais aspectos com o Plano de Desenvolvimento Institucional (2018-2022) da Univesp, analisando algumas das disciplinas dos seus cursos de graduação. A pesquisa, de natureza qualitativa, contou com o método de análise dedutivo para integrar os documentos selecionados com os dados mapeados. Concluímos que, embora a universidade seja regida pelas leis nacionais e exponha preocupações com a temática no seu Plano de Desenvolvimento Institucional, ainda enfrenta dificuldades para tornar os seus conteúdos acessíveis.

Palavras-chave: Tecnologia assistiva. Acessibilidade. Ensino a distância. Estudante com deficiência.

\section{(c) (i)}

Recebido 29/07/2021

Aceito 12/01/2022

Publicado $17 / 01 / 2022$

\section{COMO CITAR ESTE ARTIGO}

ABNT: PINHEIRO, L. A. et al. Do Direito à Educação à Necessidade de Tecnologias Assistivas para Estudantes com Deficiência: um Estudo de Caso Sobre a Univesp. EaD em Foco, v. 12, n. 1, e1557, 2022. DOI: https://doi.org/10.18264/eadf.v12i1.1557 


\section{From the Right to Education to the Need of Assistive Technologies for Students with Disabilities: a Case Study About Univesp}

\section{Abstract}

This article focused on trying to understand aspects related to the presence of technological tools and accessibility resources that promote inclusion in higher education in the distance modality. We start from normative studies and legal guidelines for understanding education as a right. We related these aspects to the Institutional Development Plan (2018-2022) of the Univesp, analyzing some of the disciplines of its undergraduate courses. The research, of a qualitative nature, relied on the deductive analysis method to integrate the selected documents with the mapped data. We concluded that, althought the university is ruled by national laws and expresses concerns with the theme in your Institutional Development Plan, it still faces difficulties in making its contents acessible.

Keywords: Assistive technology. Accessibility. Distance education. Disabled student.

\section{Introdução}

O desejo por uma educação democrática garantida como um direito e com papel emancipatório do sujeito perpassa diferentes áreas de debate. Fundamenta trabalhos como os de Paulo Freire, tão lembrado no ano de 2021 por seu centenário; motiva a alteração e renovação de leis; fomenta debates cruciais entre as áreas de educação, sociologia, direito, dentre outras, que buscam um sujeito socialmente participativo e crítico, no sentido de adquirir consciência crítica e de se compreender como sujeito histórico.

Aqui chamamos por desejo uma necessidade, uma urgência. Os três pilares levantados - democracia, direito, emancipação - tensionam-se para uma concretização social ainda em curso. A estrutura da sociedade brasileira se torna um forte obstáculo para alcançar tal desejo. Para Marilena Chauí (2020), esta é uma sociedade autoritária, vertical, hierarquizada, racista, machista, homofóbica, violenta, incapaz de aceitar o princípio de igualdade, e que considera todas as desigualdades naturais como forma de oprimir o outro, desconsiderando neste esteio a diversidade e a pluralidade humana. Vivemos ainda em uma sociedade cindida entre as carências absolutas das camadas populares e os privilégios absolutos das camadas dominantes.

Para alcançarmos uma educação acessível a todas as pessoas, que forme sujeitos emancipados e críticos de sua realidade, é preciso compreendermos, primeiro, a educação como um direito e o que está atrelado a esta compreensão. Quando direcionamos nossas atenções às pessoas com deficiência, observamos que esse direito é recém adquirido, resultante de lutas e enfrentamentos que, além de buscar democratizar e ampliar suas oportunidades, visam reduzir desigualdades que há muito incidem sobre suas vidas. Suas inserções como estudantes em instituições de ensino superior (IES) não são um processo que se encontra pronto, mas em construção e em contínuo movimento e transformação. Assim, ainda que o ingresso e matrícula deste segmento da população às IES esteja previsto por leis e diretrizes, perguntamos: apenas isso é suficiente para garantir-lhes o acesso à educação?

Tomando como base o estudo de caso da Univesp (Universidade Virtual do Estado de São Paulo), a análise do seu Plano de Desenvolvimento Institucional (PDI 2018-2022) e a ausência ou presença dos recursos de acessibilidade em seus materiais educacionais, este trabalho se propõe discutir sobre a importância 
das tecnologias assistivas no que tangencia a ideia da educação como um direito às pessoas com deficiência e, outrossim, suas possibilidades de acessá-la democraticamente, de maneira igualitária, autônoma e independente.

$\mathrm{Na}$ intenção de responder a tais questões particulares de natureza realística, pelo amparo legal, e também de natureza subjetiva, em face à inaplicabilidade do direito pela sociedade, o percurso metodológico do trabalho envolveu uma abordagem inteiramente qualitativa. Dentre a variedade de possibilidades de análise presente no escopo de uma pesquisa qualitativa, a mais adequada para atender os objetivos do trabalho foi a análise pelo método dedutivo. Isso porque a construção de argumentos dedutivos tem o propósito de explicar premissas que contextualizam o objeto de análise no espaço que o cerca (LAKATOS e MARCONI, 2017). Por meio do método dedutivo, analisamos documentos institucionais, artigos, livros e leis acerca da temática. A seleção normativa e bibliográfica para o estudo foi feita estrategicamente para fornecer indícios e argumentos que ajudem a compreender as hipóteses de pesquisa e a construção de inferências sobre a mesma.

Em um primeiro momento, levantamos aspectos que revelam a educação como direito difuso das pessoas com deficiência, procurando amparo na Constituição e legislações vigentes que abordem a tríade educação/direito/deficiência. Na sequência, analisamos o PDI da referida IES para apreender como, e se, a seguridade a este direito faz-se presente nas suas metas e objetivos. Após, versamos sobre a importância do uso de recursos de acessibilidade e de Tecnologias Assistivas (TA) na educação inclusiva na modalidade a distância. Fazemos isso apresentando características de alguns destes recursos, como as Legendas, a Língua Brasileira dos Sinais (Libras) e a Audiodescrição.

Findamos o trabalho com uma análise pontual, voltada a discriminar os recursos de acessibilidade disponibilizados pela Univesp em mais de 10 disciplinas dos cursos de graduação em Gestão Pública, Pedagogia, Matemática e Engenharia de Produção. Devido às medidas de isolamento social para minimizar o contágio do novo coronavírus (Sars-Cov-2), a coleta destes dados se delimitou ao Ambiente Virtual de Ensino e Aprendizagem (AVA) da instituição - excluindo da análise o trabalho realizado nos polos presenciais. Elegemos, como lócus de coleta de dados, todas as disciplinas em que os autores deste artigo atuaram como Facilitadores de Aprendizagem', ao logo dos quatro bimestres do ano de 2020.

Com a análise, foi possível elucidar vestígios que representam como se dá a promoção, ou não, da acessibilidade na prática na referida IES, possibilitando inferências, com o esteio teórico do trabalho, que contribuam com o debate que se localiza na interface entre Educação como Direito, Educação a Distância e Pessoas com Deficiência.

\section{A educação inclusiva como direito}

Será que consideramos a educação como um direito? A pergunta já nos induz a dizer que sim, contudo, segundo Marilena Chauí (2020), ainda estamos no processo social para compreender a educação como direito, e não como serviço ou privilégio. A marca de um direito é a sua universalidade. Nesse sentido, se opõe ao privilégio, que é a afirmação de que se possui algo em exclusividade, como o individualismo do que se tem em específico.

A educação como direito e como elemento de emancipação é fundamental para a formação cidadã, e a democratização do acesso à educação passa por vias do entendimento desta como um direito. Além do dever ético de propiciar um ambiente livre de exclusões e passível de integração social, a democratização de acesso também se associa à igualdade de oportunidades e direitos. Com garantia legalmente

1 Na Univesp, um "Facilitador de Aprendizagem" é a pessoa responsável por realizar a mediação entre os conteúdos organizados pelo professor-autor e disponibilizados no AVA, e os alunos da instituição. Os facilitadores são estudantes de diversos programas de pós-graduação das instituições conveniadas à Univesp, a saber: USP, Unesp e Unicamp. 
prevista, constante de dispositivos gerais e específicos do direito brasileiro, merecem análise quanto à sua vigência, bem como quanto à forma pela qual são (ou não) os direitos efetivamente aplicados.

Dentro do princípio de universalidade da educação como um direito, não podemos deixar de evidenciar a Constituição Federal de 1988. Pela abrangência de seus artigos, manifestou-se por advertir quaisquer formas de discriminação, resguardando a dignidade do ser humano. Desta feita, consagrado no artigo $5^{\circ}$, o Princípio da Isonomia, ou popularmente chamado de Princípio da Igualdade, prega que:

Art. $5^{\circ}$ Todos são iguais perante a lei, sem distinção de qualquer natureza, garantindo-se aos brasileiros e aos estrangeiros residentes no País a inviolabilidade do direito à vida, à liberdade, à igualdade, à segurança e à propriedade, nos termos seguintes [...]. (BRASIL, 1988)

Há de se frisar, no entanto, por meio da análise e interpretação do texto constitutivo, que o princípio da igualdade deve ser aplicado a partir de uma perspectiva material, ou substancial, não apenas formal. Isso porque a problemática da igualdade formal versus igualdade material é firmada em uma bagagem histórica e social que perpetua a subalternização de determinados grupos, devido à sua reforçada exclusão.

Assim, embora a beleza da Constituição reforce em seu texto uma regra geral, há de se reconhecer que ela não é, por si só, capaz de dissociar dos menos favorecidos o déficit histórico e social a eles inerente, cabendo ao poder público repensar a forma da atuação da Lei, principalmente partindo da análise de seus beneficiários como destinatários de medidas que promovam a efetiva redução das desigualdades havidas no meio em que vivem (GOMES, 2001).

Sobre tal aspecto, Boaventura de Sousa Santos (2003, p. 56) bem aduziu que:

Temos o direito a ser iguais quando a nossa diferença nos inferioriza; e temos o direito a ser diferentes quando a nossa igualdade nos descaracteriza. Daí a necessidade de uma igualdade que reconheça as diferenças e de uma diferença que não produza, alimente ou reproduza as desigualdades.

Constitucionalistas ${ }^{2}$ nos guiam para o entendimento de que a igualdade formal prevista na lei deve ser aplicada àqueles que se encontrem na mesma situação, garantindo que estes recebam o mesmo tratamento. Em contrapartida, a igualdade material deve possibilitar àqueles que estejam em uma situação desfavorável que recebam tratamento desigual, como forma de compensação de todos os desequilíbrios existentes, sejam eles sociais, econômicos, culturais ou, tal como o tópico da presente pesquisa, de todos os eventuais desafios suportados por pessoas com deficiência.

Ademais, o direito fundamental à igualdade também se direciona a garantir a todos o pleno exercício de outros direitos fundamentais e sociais, também previstos em nossa Carta Magna.

A educação é classificada como um direito social e previsto no artigo $6^{\circ}$ do texto constitucional, além de reforçada pelo artigo 205 e seguintes, que a instituem como "direito de todos e dever do Estado e da família" de modo que "será promovida e incentivada com a colaboração da sociedade, visando ao pleno desenvolvimento da pessoa, seu preparo para o exercício da cidadania e sua qualificação para o trabalho". (BRASIL, 1988). 
Conforme o entendimento do autor Celso Ribeiro Bastos (2000, p. 482), o mencionado artigo possui caráter bifronte, uma vez que, ao mesmo tempo em que garante a todos o direito à educação, também condiciona a responsabilidade do Estado na prestação do ensino, juntamente com o auxílio da família e da sociedade.

O papel do Estado representa sua obrigação de construir, manter e organizar escolas, democratizando o ensino por meio de sua gratuidade, zelando pela sua qualidade e respeitando a legislação pertinente. A atuação da família representa o respaldo emocional e moral da criança/adolescente, além do compromisso de colaborar com o Estado no encaminhamento de seus filhos à instituição. Por fim, a colaboração da sociedade deve existir para suprir as deficiências do Estado na promoção da educação, pela livre iniciativa e busca de melhor qualidade. (MOTTA, 1997, p. 168)

Nesse tocante, com base no direito à educação e nos munindo de todos os aspectos direcionados a uma igualdade material e não meramente formal, deduzimos que, embora o texto constitucional seja extremamente garantista, ainda corresponde a uma realidade geral, que deve ser direcionada e aplicada de acordo com as especificidades de cada grupo, possibilitando que surta efeitos positivos. Para tanto, a legislação brasileira não pôde manter-se estática. A edição de dispositivos específicos, tais como a Lei n 9.394/96 (Lei de Diretrizes e Bases da Educação Nacional) e a Lei n 10.172/2001 (Plano Nacional de Educação) também contribuem para que a educação seja firmada e garantida como direito.

Ainda, apresentando uma visão mais direcionada no concernente ao direito à educação de pessoas com deficiência, a Portaria $n^{\circ} 3.284 / 03$ dispõe os requisitos mínimos de acessibilidade de pessoas com deficiências para a autorização e reconhecimento de cursos e de credenciamento de instituições. Estes requisitos, contudo, limitam-se a recursos materiais e de acompanhamento de intérprete para a formação presencial, não sendo específica quanto a elementos essenciais para a Educação a Distância.

É imprescindível, no mesmo sentido, mencionarmos a própria Lei n 13.146/2015, popularmente chamada de "Estatuto da Pessoa com Deficiência", a qual é destinada, conforme seu artigo $1^{\circ}$, a "assegurar e a promover, em condições de igualdade, o exercício dos direitos e das liberdades fundamentais por pessoa com deficiência, visando à sua inclusão social e cidadania" (BRASIL, 2015). Seu texto traz, em capítulo próprio, disposições exclusivamente voltadas ao direito à educação (capítulo IV), sob uma perspectiva inclusiva, direcionada a todos os níveis de aprendizado.

Ademais, notamos que o estatuto, ainda que de forma geral e esparsa (desvinculada do capítulo à educação) reconheça que existem barreiras tecnológicas a serem superadas, conforme seu artigo $3^{\circ}$, III e IV,$f^{3}{ }^{3}$ o que pode ser vinculado ao ensino a distância, justamente devido à negligência de acessibilidade pela utilização de métodos, plataformas, videoaulas e provas excludentes.

Seguindo o discurso aqui delineado sobre a democratização de acesso à educação como direito, incluir aqueles que historicamente foram excluídos significa oferecer mudanças para manifestação do humano, da subjetividade, e não a simples readequação físico-espacial dos sujeitos (ROSS, 2004). Tornase necessário dispor de condições adequadas para que se possa participar dos diversos espaços sociais, para manifestar sua aprendizagem e suas diferenças. "A manifestação ou a garantia da heterogeneidade lhes confere o direito de pertencer, de participar, de constituírem-se como humanos, e de não serem rejeitados, pois a padronização das respostas humanas não pode mais ser exigida" (ROSS, 2004, p. 204). Cada sujeito dispõe de uma dimensão individual de aprendizagem processada de forma coletiva.

3 Art. $3^{\circ}$ Para fins de aplicação desta Lei, consideram-se: III - tecnologia assistiva ou ajuda técnica: produtos, equipamentos, dispositivos, recursos, metodologias, estratégias, práticas e serviços que objetivem promover a funcionalidade, relacionada à atividade e à participação da pessoa com deficiência ou com mobilidade reduzida, visando à sua autonomia, independência, qualidade de vida e inclusão social; IV - barreiras: qualquer entrave, obstáculo, atitude ou comportamento que limite ou impeça a participação social da pessoa, bem como o gozo, a fruição e o exercício de seus direitos à acessibilidade, à liberdade de movimento e de expressão, à comunicação, ao acesso à informação, à compreensão, à circulação com segurança, entre outros, classificadas em: $\mathrm{f}$ ) barreiras tecnológicas: as que dificultam ou impedem o acesso da pessoa com deficiência às tecnologias. 
As dimensões individuais guardam a diferença e exigem diferentes recursos. "A aprendizagem é sempre mediada por instrumentos, signos e procedimentos que possibilitam relações entre os sujeitos e objetos e entre os sujeitos" (ROSS, 2004, p. 207).

O Decreto n 5.296, publicado em dezembro de 2004 (BRASIL, 2004), dispõe, no Capítulo Vl, sobre o acesso à informação e comunicação, em que torna obrigatória a acessibilidade nos portais e sites eletrônicos de administração pública na rede mundial de computadores, para garantia das pessoas com deficiência ao pleno acesso aos conteúdos disponíveis. Há outros decretos e normativas que dispõem sobre o acesso das pessoas com deficiência à informação e educação, mas que neste espaço reduzido convém, por fim, sublinhar que as normativas são alteradas constantemente para atender de forma adequada às mudanças sociais e educacionais mais recentes. Observamos que, na modalidade de Educação a Distância, ainda há que se conectar as normativas de acessibilidade às discussões sobre inclusão e processos de ensino-aprendizagem.

Dentro do escopo deste artigo, em se tratando de normativas internas à Univesp, observamos que o Plano de Desenvolvimento Institucional (PDI) que compreende os anos de 2018 e 2022, tem como objetivo a "[...] universalização do acesso à educação formal e à educação para cidadania" (UNIVESP, 2018, p. 07) através da formação de educadores e outros profissionais, como instituição dedicada ao ensino, pesquisa e extensão.

Dentre os oito objetivos listados pela instituição (UNIVESP, 2018, p. 11), o primeiro diz respeito à ampliação do acesso ao ensino superior. Na organização didático-pedagógica (UNIVESP, 2018, p. 25) listamse elementos de acessibilidade em que:

Todos os conhecimentos a serem transmitidos, no entanto, serão disponibilizados em múltiplas linguagens, reconhecendo tanto a importância da inclusão para os diversos tipos de portadores de deficiências quanto a diversidade na forma com que as pessoas aprendem. Assim, as videoaulas de conhecimentos básicos são legendadas e com tradução para LIBRAS (Linguagem Brasileira de Sinais), os textos e livros básicos são disponibilizados em MP3 para audição de pessoas que necessitam ou para aquelas que gostam desse modelo para apropriação de conhecimentos. Além disso, existe a preocupação com questões de acessibilidade no AVA da Univesp, garantindo o acesso de uma maior diversidade de pessoas aos conteúdos oferecidos pelos cursos.

Além da afirmação de que "Há condições de acessibilidade em todas as instalações" dos Polos presenciais de ensino (UNIVESP, 2018, p. 85), dispõe como parte dos programas de extensão da Univesp, um “Programa de Acessibilidade" previsto para execução entre 2018 e 2020, para “Desenvolver metodologias para educação especial" (UNIVESP, 2018, p. 44).

No PDI (UNIVESP, 2018, p.89), afirma-se que:

As políticas de educação inclusiva da Univesp pautam-se na legislação vigente que assegura à pessoa com deficiência ou mobilidade reduzida os direitos fundamentais, além de possibilidades de adaptações físicas, instrumentais e tecnológicas que facilitam a execução de tarefas. A limitação da pessoa não diminui seus direitos, como cidadã, de fazer parte da sociedade tal qual qualquer outra.

Dessa forma, é preciso discutir que meios de acessibilidade se apresentam como o mínimo para que o processo de aprendizagem na interação coletiva ocorra. A seguir, apresenta-se uma síntese dos recursos 
de acessibilidade presentes nos meios educativos, para, em seguida, tratar especificamente de quais recursos são observados na Univesp.

\title{
3. Recursos de acessibilidade na educação
}

Ao considerar aspectos das leis e diretrizes legais apresentadas, seguimos no pressuposto de que é preciso apreender como vem sendo relatada na literatura a prática das normativas que versam sobre a implementação de recursos de acessibilidade. Recursos estes que, por sua vez, possibilitam a permanência dos discentes na instituição de ensino, bem como o auxiliam nos seus percursos de ensino-aprendizagem - fundamentais, quando estamos tratando sobre uma educação emancipatória. Para início, podemos ressaltar que abordar o paradigma da inclusão dispõe de uma necessidade de compreender que a inclusão não abarca um todo homogêneo e previsível. Dessa forma, o tema é exposto às barreiras que se manifestam de forma dinâmica e pouco previsível, variando de contexto para contexto e de pessoa para pessoa (SASSAKI, 2009).

Assim, para esta discussão, é fundamental ter uma visão transcendente sobre o percurso histórico que levou os estudantes com deficiência ao acesso à educação. Por meio de embates amparados por enfoques sociais, políticos e de saúde, o princípio da educação democrática foi suprimido frente ao direito difuso do ensino para todos por muito tempo (SILVA; BECHE; SOUZA, 2011). Mais especificamente, apenas em meados do século XX é que a Declaração Universal dos Direitos Humanos, da Organização das Nações Unidas (ONU, 1948) impulsionou que a pauta se fizesse presente nas agendas de formuladores de políticas públicas educacionais. Entretanto, foi somente em 1988, com a nossa Constituição Federal, e em 1996, com a Lei de Diretrizes e Bases da Educação, que o princípio da educação democrática foi posto em voga no nosso país.

Se olharmos para a Declaração dos Direitos da Pessoa Deficientes, da ONU (1975), encontraremos a seguinte premissa:

\begin{abstract}
As pessoas deficientes têm o direito inerente de respeito por sua dignidade humana. As pessoas deficientes, qualquer que seja a origem, natureza e gravidade de suas deficiências, têm os mesmos direitos fundamentais que seus concidadãos da mesma idade, o que implica, antes de tudo, o direito de desfrutar de uma vida decente, tão normal e plena quanto possível.
\end{abstract}

Para tanto, é necessário que a sociedade se atente às barreiras e os impeditivos que ela mesma construiu - como as de ordem arquitetônica, comunicacional, metodológica, instrumental, programática e atitudinal - que, para Sassaki (2009), se constituem como as seis dimensões que a acessibilidade deve abranger, no que concerne uma sociedade mais inclusiva às pessoas com deficiência. Essas dimensões, quando não atendidas e tornadas barreiras, dificultam e impedem as pessoas com deficiência de desfrutarem uma vida plena e autônoma; de acessarem e de usufruírem os aparatos, espaços, instrumentos e conhecimentos gestados pela humanidade ao longo de sua existência. Isto é, que a sociedade e, consequentemente as instituições educacionais, sejam mais acessíveis, a saber, que haja

[...] possibilidade e condição de alcance para utilização, com segurança e autonomia, de espaços, mobiliários, equipamentos urbanos, edificações, transportes, informação e comunicação, inclusive seus sistemas e tecnologias, bem como de outros serviços e instalações abertos ao público, de uso público ou privados de uso coletivo, tanto na zona urbana como na rural, por pessoas com deficiência ou mobilidade reduzida. (BRASIL, 2017, p. 47) 
Dentre alguns dos recursos que visam possibilitar que isso ocorra, estão as chamadas Tecnologias Assistivas (TA). As Tecnologias Assistivas são utilizadas para identificar todo o tipo de recurso e/ou serviço que contribui e propicia uma ampliação nas habilidades funcionais de uma pessoa, tenha ela uma deficiência ou não. Consequentemente, a existência e o emprego de tais recursos auxiliam na diminuição das barreiras impeditivas e promoção de uma vida mais independente e autônoma.

Nesta perspectiva, estes recursos podem ser entendidos como “[...] todo e qualquer item, equipamento ou parte dele, produto ou sistema fabricado em série ou sob medida, utilizado para aumentar, manter ou melhorar as capacidades funcionais das pessoas com deficiência" (BERSCH, 2017, p. 3). Com base nesses critérios, Cook e Polgar (1995, s/p.) definiram a Tecnologia Assistiva como "[...] uma ampla gama de equipamentos, serviços, estratégias e práticas concebidas e aplicadas para minorar os problemas funcionais encontrados pelos indivíduos com deficiência".

No Brasil, o Comitê de Ajudas Técnicas (CAT), instituído pela Portaria n. 142, de 16 de novembro de 2006, propõem o seguinte conceito para as TAs:

Tecnologia Assistiva é uma área do conhecimento, de característica interdisciplinar, que engloba produtos, recursos, metodologias, estratégias, práticas e serviços que objetivam promover a funcionalidade, relacionada à atividade e participação de pessoas com deficiência, incapacidades ou mobilidade reduzida, visando sua autonomia, independência, qualidade de vida e inclusão social. (BRASIL, 2009, p. 09, grifo nosso)

No contexto educacional, são exemplos de TA os mouses diferenciados, os teclados virtuais com varreduras e acionadores, softwares de comunicação alternativa, leitores de texto, textos ampliados, textos em Braille, textos com símbolos, mobiliário acessível, recursos de mobilidade pessoal, entre tantos outros. As TAs, portanto, podem variar de um simples recurso físico até um complexo sistema computadorizado, a depender das necessidades específicas de cada sujeito. ${ }^{4}$

Assim, percebe-se como estes recursos são de fundamental importância à vida das pessoas com deficiência, principalmente pelo viés educacional. Não à toa, o termo também aparece no Instrumento de Avaliação de Cursos de Graduação Presencial e a Distância (BRASIL, 2017), enfatizando o emprego de tais recursos no acesso e na permanência dos estudantes com deficiência nas instituições de ensino. Em seu glossário, entre inúmeros verbetes, iremos encontrar um, em específico, que dialoga diretamente com a realidade da educação a distância, a acessibilidade digital:

Ausência de barreiras na disponibilidade de comunicação, de acesso físico, de tecnologias assistivas, compreendendo equipamentos e programas adequados, de conteúdo e apresentação da informação em formatos alternativos. (BRASIL, 2017, p. 47, grifos nossos)

De maneira geral, tanto a aquisição quanto a implementação dos recursos de TA requerem estudo aprofundado de cada aluno, considerando as suas diferenças individuais e suas necessidades educacionais específicas. Tratar de recursos de acessibilidade envolve considerar as representações sociais, políticas, cognitivas e valorativas do contexto a qual os estudantes, docentes e gestores estão inseridos (ROCHA; MIRANDA, 2009).

4 O conceito de necessidades específicas (DINIZ, 2012), no contexto educacional, refere-se ao grupo de estudantes que necessitam de apoio e atenção especial na escola. Ou seja, refere-se ao fato de se encaixar em determinadas condições e apresentar alguma dificuldade. Dentro desse grupo existe uma grande variedade de estudantes, não apenas aqueles que possuem algum tipo de deficiência. 
Porém, quando falamos da Educação a Distância, a maior parte dos recursos educacionais já está posta e finalizada nos Ambientes Virtuais de Aprendizagem ${ }^{5}$ antes mesmo de os alunos terem contato com ele: os textos já foram selecionados, as videoaulas já foram gravadas, as atividades avaliativas e somativas já foram produzidas e o designer instrucional já organizou esses materiais com antecedência na plataforma. O que ocorre, então, quando um estudante com deficiência se matricula no curso e o mesmo não apresenta nenhum tipo de Tecnologia Assistiva para auxiliá-lo? Todas as respostas possíveis que este questionamento reflexivo pode levantar abarcarão consequências a duas esferas, a institucional (no sentido de gestão e corpo docente) e a discente. Dessa forma, percebe-se que não basta abordar o tema apenas no Plano de Desenvolvimento Institucional, aliando-se às diretrizes e normativas legais e constitucionais; é preciso ir além. Pois, garantir uma educação democrática e inclusiva não se reduz ao ato de matricular pessoas com deficiência e/ou alunos com necessidades educacionais especiais na instituição. Apesar de a matrícula ser um passo importantíssimo nessa direção, incluir significa permitir aos estudantes apropriarem-se da totalidade dos saberes e das oportunidades educacionais oferecidas de forma autônoma e independente. Isto é, a inclusão precisa ser compreendida como um processo de equiparação de oportunidades de aprendizagem e de participação (SASSAKI, 2009).

Nesse sentido, lidar com a inclusão no Ensino Superior, seja na modalidade presencial ou a distância, não é algo que se solucione só com a criação de decretos legais abrangentes. Há que se pautar por uma mudança profunda na estrutura educacional e compreensão da questão da acessibilidade em suas seis dimensões (SASSAKI, 2009). Se não atendidas essas dimensões, impede-se não só o acesso, mas também a permanência de pessoas com deficiência na trajetória de suas formações intelectuais e profissionais (ROCHA, MIRANDA, 2009), o que responde, em parte, o questionamento levantado acima.

Desse modo, para proporcionar condições apropriadas de aprendizado, cabe às instituições de ensino a distância providenciar o oferecimento de TAs de acordo com as demandas de cada aluno com deficiência. Segundo estudo feito por Dillenburg e Checchin (2018), o ensino a distância brasileiro ainda precisa investir em recursos e suportes adequados e com equipes especializadas, para acompanharem e possibilitarem que os processos de ensino-aprendizado dos estudantes sejam efetivos - o que, consequentemente, acarreta efetivos e reais processos de inclusão e de democratização do ensino.

Ainda, Dillenburg e Checchin (2018) observaram que, dentre os recursos e suportes necessários para uma efetiva inclusão, estão a disponibilização de tutores intérpretes e tutores de atendimento educacional especializado; a oferta semanal de plantões de acessibilidade nos polos; e a implementação de Tecnologias Digitais da Informação e da Comunicação (TDIC) na plataforma virtual - como a utilização de legendas em materiais audiovisuais, a utilização de ferramentas sonoras de audiodescrição e a utilização da Língua Brasileira dos Sinais (Libras) (SILVA, 2018).

Sobre a utilização de legendas, implica a inserção de transcrição de diálogos, de efeitos sonoros, detaIhes do ambiente e demais informações que podem estar presentes em um conteúdo utilizado nas aulas ou nos materiais complementares. (SILVA, 2018). Para uma elaboração de legendas padronizadas e condizentes com as referências dadas por especialistas, foi criada a norma 16452, pela Associação Brasileira de Normas Técnicas (ABNT), a qual delimita o uso de características como fonte, cor, espaçamento e tempo de exibição (BRASIL, 2016).

A utilização de audiodescrição caminha na mesma direção de promover acessibilidade na comunicação, mas utiliza o registro oral para descrever qualquer registro visual (SILVA, 2018). ${ }^{6}$ Assim como as legendas, a audiodescrição também possui diretrizes delimitadas pela ABNT 16452, que ressalta

5 No escopo desta pesquisa, o AVA utilizado pela XXXX em 2020 era o Canvas LMS, customizado por designers da própria universidade.

6 A audiodescrição é considerada uma tradução intersemiótica, ou também tradução audiovisual, que transforma o signo visual para o verbal. Ela possuiu várias nuances e perspectivas teórico-práticas, algumas mais técnicas outras mais poéticas. Por ser uma área nova, ainda está em constante experimentação e transformação (CORREIA, 2017). 
o uso de termos adequados para facilitar a compreensão, tais como tempo verbal, tipo de linguagem utilizada, ambientação e forma de apresentar os personagens de um contexto. Assim, quando há uma determinada atividade ou conteúdo que apresenta imagens, e que elas se relacionam de maneira direta e imprescindível com os conteúdos apresentados, somente os leitores de tela não são suficientes, pois eles não conseguem, sozinhos, transformar em palavras as imagens apresentadas.

Já a Libras é atualmente regulamentada na legislação brasileira por meio do Decreto n 5626/2005, que define a pessoa surda como “[...] aquela que, por ter perda auditiva, compreende e interage com o mundo por meio de experiências visuais, manifestando sua cultura principalmente pelo uso da Língua Brasileira de Sinais (Libras)". Apesar de compreendermos que nem toda pessoa com deficiência auditiva utiliza Libras, assim como nem toda pessoa cega lê em Braile (TORRES, MAZZONI, MELLO, 2007), a comunicação por meio dos sinais pode ocupar um importante espaço na vida das pessoas com deficiência auditiva, fazendo com que seja extremamente necessária à sua utilização em diversos campos sociais, incluindo a educação (SILVA, 2018).

Portanto, consideramos que, nos tempos hodiernos, adequar aos requisitos exigidos pelos recursos de acessibilidade, não é algo intangível ante as inúmeras fontes de informações e parâmetros normativos que auxiliam nesse processo. No mais, não devemos desconsiderar que a implementação desses recursos exige investimentos financeiros, mão de obra qualificada, mudanças nos planejamentos pedagógicos tradicionais e comprometimento coletivo. A seguir, apresentamos quais e como as TAs estão presentes na Univesp e como suas ausências implicam uma não-acessibilidade dos conteúdos ofertados.

\section{Tecnologias assistivas na Univesp}

Devido aos protocolos de distanciamento social, adotados na tentativa de minimizar a pandemia da covid-19, os polos da Univesp passaram a operar de modo virtual, bem como as provas passaram a ser on-line. Este contexto fez com que o foco da pesquisa prática se voltasse para as disciplinas facilitadas pelas autoras e pelo autor deste artigo durante todo o ano de 20207. Para análise das disciplinas, foram considerados os seguintes aspectos abordados por Dillenburg e Checchin (2018) quanto às Tecnologias Digitais da Informação e da Comunicação (TDIC) na plataforma virtual, a saber: a utilização de legendas em materiais audiovisuais, a utilização de ferramentas sonoras de audiodescrição e a utilização da Língua Brasileira dos Sinais (Libras) (SILVA, 2018).

Foi feito o levantamento das ferramentas de TA disponíveis em cada uma das disciplinas. A tabela abaixo apresenta conteúdos comuns a todas elas e constam nos conteúdos semanais, que são: os textos de introdução dos conteúdos da semana, o Desafio (que está atrelado à questão a ser discutida no fórum temático), as orientações de estudo, as videoaulas e os textos-base. Não foram analisados os materiais das seções: revisitando conhecimentos, textos de apoio, aprofundando o tema, fórum de dúvidas e atividades avaliativas.

7 No momento em que esta pesquisa foi realizada, e os dados foram levantados, verificou-se que a instituição não possui uma organização estrutural que possa fornecer dados mais concretos e sensíveis para análise do estudo de caso em questão, como, por exemplo, o quantitativo dos estudantes com algum tipo de deficiência matriculados na instituição ou quais recursos Ihes são necessários em vias de que os materiais disponibilizados se tornem acessíveis. A escolha por disciplinas facilitadas pelo autor e pela autora são consequências diretas da ausência de dados disponíveis. 
Quadro 1: Presença de Tecnologias Assistivas em um conjunto de disciplinas

\begin{tabular}{|c|c|c|c|}
\hline & \multicolumn{3}{|c|}{ Tecnologias Assistivas pesquisadas } \\
\hline $\begin{array}{l}\text { Disciplinas } \\
2020\end{array}$ & $\begin{array}{l}\text { Legendas videoaulas } \\
\text { (automática / closed } \\
\text { caption - CC) }\end{array}$ & $\begin{array}{l}\text { Audiodescrição das } \\
\text { imagens contidas } \\
\text { nos textos e nas } \\
\text { videoaulas }\end{array}$ & $\begin{array}{l}\text { Libras } \\
\text { Videoaulas e } \\
\text { textos }\end{array}$ \\
\hline Leitura e Produção de Textos & $\begin{array}{l}21 \text { vídeos. } \\
\text { Todos têm autom. } \\
\text { Nenhum tem CC. }\end{array}$ & Não possui. & Não possui. \\
\hline $\begin{array}{l}\text { Fundamentos e Práticas no } \\
\text { Ensino de História }\end{array}$ & $\begin{array}{l}15 \text { vídeos. } \\
\text { Todos têm autom. } \\
\text { Nenhum tem CC. }\end{array}$ & Não possui. & Não possui. \\
\hline Escola e Cultura & $\begin{array}{l}13 \text { vídeos. } \\
\text { Todos têm autom. } \\
\text { Nenhum tem CC. }\end{array}$ & Não possui. & Não possui. \\
\hline Inglês & $\begin{array}{l}30 \text { vídeos. } \\
\text { Todos têm autom. } \\
03 \text { tem CC (não produzida } \\
\text { pela Univesp). }\end{array}$ & Não possui. & Não possui. \\
\hline $\begin{array}{l}\text { Educação e Cultura Corporal: } \\
\text { fundamentos e práticas }\end{array}$ & $\begin{array}{l}46 \text { vídeos. } \\
45 \text { têm autom. } \\
\text { Nenhum tem CC. }\end{array}$ & Não possui. & Não possui. \\
\hline $\begin{array}{l}\text { Políticas Educacionais e } \\
\text { Estrutura e Organização da } \\
\text { Educação Básica }\end{array}$ & $\begin{array}{l}25 \text { vídeos. } \\
21 \text { têm autom. } \\
02 \text { têm CC (sendo que } 1 \text { é } \\
\text { para idioma estrangeiro). }\end{array}$ & Não possui. & Não possui. \\
\hline $\begin{array}{l}\text { Gestão de Compras e Licitação } \\
\text { Pública }\end{array}$ & $\begin{array}{l}09 \text { vídeos. } \\
\text { Todos têm autom. } \\
\text { Nenhum tem CC. }\end{array}$ & Não possui. & Não possui. \\
\hline Economia II & $\begin{array}{l}14 \text { vídeos. } \\
\text { Todos têm autom. } \\
\text { Nenhum tem CC. }\end{array}$ & Não possui. & Não possui. \\
\hline Gestão Documental & $\begin{array}{l}14 \text { vídeos. } \\
\text { Todos têm autom. } \\
\text { Nenhum tem CC. }\end{array}$ & Não possui. & Não possui. \\
\hline P.I. de licenciatura I & $\begin{array}{l}14 \text { vídeos. } \\
13 \text { têm autom. } \\
\text { Nenhum tem CC. }\end{array}$ & Não possui. & Não possui. \\
\hline Didática & $\begin{array}{l}10 \text { vídeos. } \\
03 \text { têm autom. } \\
06 \text { têm CC. }\end{array}$ & Não possui. & Não possui. \\
\hline $\begin{array}{l}\text { Metodologia para a Educação } \\
\text { Básica: Resolução de Problemas }\end{array}$ & $\begin{array}{l}22 \text { vídeos. } \\
21 \text { têm autom. } \\
\text { Nenhum tem CC. }\end{array}$ & Não possui. & Não possui. \\
\hline Introdução à Linguística & $\begin{array}{l}22 \text { vídeos. } \\
\text { Todos têm autom. } \\
\text { Nenhum tem CC. }\end{array}$ & Não possui. & Não possui. \\
\hline
\end{tabular}


De acordo com os dados levantados e analisados, nenhuma das disciplinas facilitadas pelas autoras e autor deste artigo possui recursos acessíveis que garantam que estudantes com deficiência visual ou auditiva tenham acesso, de maneira autônoma e independente, aos conteúdos programáticos, indo na contramão da noção de direito à educação, garantido pelas legislações vigentes, como exposto no início deste trabalho.

O quadro acima aponta a presença ou ausência de legendas, audiodescrição e Libras. No caso das legendas, foram distinguidos dois tipos, as legendas automáticas, vinculadas diretamente à plataforma Youtube, e as de tipo Closed Caption. As legendas automáticas são transcrições criadas automaticamente por tecnologias de reconhecimento de fala usadas pelo Youtube, onde se vinculam as videoaulas disponíveis na universidade em questão. Diferente dessas legendas automáticas, Closed Caption transcreve não apenas as falas, como também apresenta em forma de texto outras informações, como barulhos de fundo, sons que compõem a cena, trilhas sonoras.

Através dessa diferenciação, é possível perceber de imediato que as legendas automáticas não são tão funcionais, pois há elementos sonoros ignorados que são importantes para a compreensão da informação e mesmo para se proporcionar uma experiência perceptiva mais ampla. Além disso, a tecnologia de reconhecimento de fala, utilizada pelas legendas automáticas, ainda é muito precária. Seja por uma interferência sonora de fundo, efeito de trilha, ou mesmo pela dicção ou sotaque do falante, há nuanças comunicativas que a tecnologia não consegue identificar, o que gera trocas de palavras e/ou termos que modificam o conteúdo dos vídeos. Essa troca dificulta e, às vezes, impossibilita a compreensão do material fornecido.

Não é também disponibilizado, no conteúdo analisado, materiais com Língua Brasileira de Sinais (Libras) nem para os vídeos, nem para os textos. A Univesp não fornece uma ferramenta interna para Libras, apesar de indicar um recurso externo produzido pelo Governo Federal, o VLibras ${ }^{8}$. Como se trata de uma ferramenta externa e não vinculada à instituição, como acontece também com as legendas geradas internamente ao Youtube, não há um sistema de suporte ou garantias de funcionamento, podendo ocorrer incompatibilidades por desatualização ou mesmo não permanecer disponível a acesso.

Nos materiais analisados, também não há incidência da audiodescrição, seja em material audiovisual ou imagético-textual. Na estrutura das disciplinas da Univesp, logo após a introdução do assunto a ser tratado em cada uma das semanas, há uma seção chamada "Desafio", que se relaciona com uma atividade de aprendizagem geralmente a ser desenvolvida pelos estudantes nos fóruns temáticos das turmas. Nesta seção de Desafio, é comum haver gráficos, imagens e/ou fotos e cards com informações que, somadas ao texto escrito, tem por função estimular o pensamento crítico e a interação. Uma vez que não há recursos de audiodescrição das imagens, parte do conteúdo se faz inacessível para as pessoas com deficiência visual. E este é apenas um dos exemplos que podemos citar de dificuldade que um estudante com deficiência se depara no percurso de desenvolvimento do pensamento crítico em relação à coletividade em que está inserido.

Dada a natureza qualitativa da pesquisa e dedutiva do método de análise, constata-se que, apesar de o PDI do período de 2018-2022 apontar como objetivos a disponibilização dos conteúdos em Libras para estudantes com deficiência auditiva e áudios de MP3 para estudantes com deficiência visual, tais recursos não se materializaram no recorte analisado neste artigo.

\section{Conclusão}

A legislação brasileira é cristalina ao determinar o direito à igualdade entre todos e todas, estimulando e criando diretrizes específicas para que a sociedade se movimente de maneira mais abrangente e inclusiva. Entretanto, no que tange os direitos de pessoas com deficiência, ainda que a legislação esteja inclinada a modificar o atual cenário de invisibilidade, há barreiras rígidas o suficiente para sua efetivação.

8 Disponível em: < https://www.gov.br/governodigital/pt-br/vlibras>. Acesso em: 06 mai 2021. 
Nesta pesquisa, verificamos como a problemática se porta no tocante à educação superior pública, em específico na Univesp. Afinal, embora a lei exista, sua promoção ainda se encontra prejudicada, ao passo em que não basta o mero preenchimento de vagas, mas sim de meios para que tais vagas sejam aproveitadas, a educação encontre seu propósito e o curso seja concluído.

Para que o acesso à educação seja equalitário, realizado de maneira autônoma e independente, se fazem necessárias a implementação e a disponibilização de recursos e tecnologias assistivas que tornem os conteúdos programáticos ofertados nos Ambientes Virtuais de Aprendizagem em materiais acessíveis e, assim, possíveis de serem apreendidos por uma diversificada gama de sujeitos, sejam eles pessoas com deficiência ou não.

A tecnologia atual evidencia que a acessibilidade é possível. Para aprofundarmos a questão, o estudo de caso da Univesp, com um recorte de disciplinas facilitadas pelas autoras e autor deste artigo, em 2020, evidenciou que, embora a universidade seja regida pelas leis nacionais e exponha preocupações com a temática no Plano de Desenvolvimento Institucional (PDI), pouco fez em vias de tornar os seus conteúdos acessíveis.

O estudo dos dados referentes às Tecnologias Assistivas indicou que os recursos de Libras e legendas, quando disponíveis, foram produzidos por plataformas externas à Univesp, não concretizando a responsabilidade de fornecimento e garantia de acesso sem instabilidades e imprecisões de informação. Dessa forma, a inexistência de Libras, legendas e audiodescrição, por parte da Instituição, impede que estudantes com deficiências sensoriais tenham acesso irrestrito aos conteúdos presentes em suas graduações e necessários não só às suas formações como ao desenvolvimento de um pensamento crítico reflexivo, seja com base nas discussões propostas nos materiais ou a partir deles.

Nesse sentido, pensar para além da legislação se faz necessário. Uma lei meramente formal, sem aplicabilidade prática, perde seus fundamentos e paira em vagueza. Obviamente, é necessária a movimentação institucional, com investimento de recursos para efetivar a acessibilidade, fazendo jus à igualdade a partir da promoção de boas práticas que materialmente promovam a inclusão.

\section{Referências}

BASTOS, C. R.; MARTINS, I. G. da S. Comentários à Constituição Brasileira. 8. v. São Paulo: Saraiva, 2000. p. 482.

BERSCH, R. Introdução à tecnologia assistiva. Porto Alegre: Assistiva - Tecnologia e Educação, 2017.

BRASIL. Constituição da República Federativa do Brasil de 1988. Diário Oficial da União. Poder Legislativo, Brasília, DF, 5 out. 1988. Disponível em: http://www.planalto.gov.br/ccivil_03/constituicao/constituicaocompilado.htm. Acesso em 02 set. 2019.

BRASIL. Decreto 5.626, de 22 de dezembro de 2005. Regulamenta a Lei n 10.436, de 24 de abril de 2002, que dispõe sobre a Libras, e o art. 18 da Lei $n^{\circ}$ 10.098, de 19 de dezembro de 2000. Diário Oficial da União: Seção 1, Brasília, DF, p.28-32, 23 dez. 2005.

BRASIL. Instituto Nacional de Estudos e Pesquisas Educacionais Anísio Teixeira-Inep. Instrumento de Avaliação de Cursos de Graduação Presencial e a distância. 2017. Disponível em: https://download.inep.gov.br/educacao_superior/avaliacao_cursos_graduacao/instrumentos/2017/curso_autorizacao.pdf Acesso em: 03 jan. 2020.

BRASIL. Lei n 13.146, de 06 de julho de 2015. Institui a Lei Brasileira de Inclusão da Pessoa com Deficiência (Estatuto da Pessoa com Deficiência). Diário Oficial da União. Poder Legislativo, Brasília, DF, 06 de julho de 2015. Disponível em: http://www.planalto.gov.br/ccivil_03/_ato2004-2006/2004/decreto/ d5296.htm Acesso em: 10 jan. 2021. 
BRASIL. Referenciais de Qualidade para Educação Superior a Distância. 2007. Disponível em: http:// portal.mec.gov.br/seed/arquivos/pdf/legislacao/refead1.pdf. Acesso em: 12 dez. 2020.

BRASIL. Subsecretaria Nacional de Promoção dos Direitos da Pessoa com Deficiência. Comitê de Ajudas Técnicas. Tecnologia Assistiva. Brasília: CORDE, 2009.

CHAUÍ, M. de S. \#1 Mesa Produção de conhecimento e emancipação social: Diálogo com Marilena Chauí. Youtube, 10 set 2020. Disponível em: <https://www.youtube.com/watch?v=1obcDvC1JIY>. Acesso em: 10 mar 2021.

COOK, A.; POLGAR, J. M. Assistive Tecnologies: Principles and Practice, Missouri: Mosby- Year Book, 1995.

CORREIA, J. B. S. Áudio-descrição na Manifestações Artístico Culturais: Uma tradução Intersemiótica. RELACult - Revista Latino-Americana de Estudos em Cultura e Sociedade. V.03, ed. especial, artigo n.526, p.1-15, Dez. 2017.

DILLENBURG, A. I.; CHECCHIN, A. F. Novas realidades no ensino superior a distância: a inclusão de universitários com deficiência. Interinstitucional Artes de Educar, Rio de Janeiro, v. 4, n. 1, p. 26 - 42, jan./ abr. 2018.

DINIZ, M. Inclusão de pessoas com deficiência e/ou necessidades específicas: avanços e desafios. São Paulo: Autêntica Editora, 2012.

GOMES, J. B. B. A recepção do instituto da ação afirmativa pelo Direito Constitucional brasileiro. Revista de Informação Legislativa, Brasília, a. 38, n. 151, p. 129-151, jul./set. 2001. Disponível em: https:// www2.senado.leg.br/bdsf/bitstream/handle/id/705/r151-08.pdf. Acesso em: 07 jul. 2020.

LAKATOS E. M.; MARCONI, M. de A. Fundamentos de metodologia científica. São Paulo: Atlas 2017.

MANZINI, E. J. Tecnologia assistiva para educação: recursos pedagógicos adaptados. In: Ensaios pedagógicos: construindo escolas inclusivas. Brasília: SEESP/MEC, p. 82-86, 2005.

MOTTA, E. de O. Direito educacional e educação no século XXI: com comentários à nova Lei de Diretrizes e Bases da Educação Nacional. Brasília: UNESCO, 1997. p. 168.

ORGANIZAÇÃO DAS NAÇÕES UNIDAS (ONU). Declaração dos Direitos das Pessoas Deficientes. Aprovada pela Assembleia Geral da ONU, em 9 de dezembro de 1975.

ROCHA, T. B.; MIRANDA, T. G. Acesso e permanência do aluno com deficiência na instituição de ensino superior. Educação Especial, Santa Maria, v. 22, n. 34, p. 197-212, maio/ago. 2009.

ROSS, P. R. Conhecimento e aprendizado cooperativo na inclusão. Educar, Curitiba, n.23, p. 203-224, 2004. Disponível em: https://www.scielo.br/pdf/er/n23/n23a13.pdf. Acesso em: 10 jan. 2021.

SANTOS, B. de S. Introdução: para ampliar o cânone do reconhecimento, da diferença e da igualdade. In: SANTOS, Boaventura de Sousa. Reconhecer para libertar: os caminhos do cosmopolitaníssimo multicultural. Rio de Janeiro: Civilização Brasileira, 2003. p. 56.

SARLET, I. W.; MARINONI, L. G.; MITIDIERO D. Curso de direito constitucional. 7. ed. São Paulo: Saraiva Educação, 2018. p. 618.

SASSAKI, R. K. Inclusão: Acessibilidade no lazer, trabalho e educação. Rev. Nacional de Reabilitação, São Paulo, n. 12, v. 1, p. 10-16, mar. 2009.

SILVA, F. B. da S. Acessibilidade Digital. Textos eletrônicos, nov. 2018. Disponível em: https://www.researchgate.net/publication/328955448_ACESSIBILIDADE_DIGITAL_-_Textos_Eletronicos\#read. Acesso em: 08 jan. 2021. 
SILVA, S. C. da; BECHE, R. C. E.; SOUZA, M. V. de. A Acessibilidade na Educação a Distância. In: VIII Congresso Brasileiro de Ensino Superior a Distância, 2011, Ouro Preto. Anais [...]. Ouro Preto: Associação Universidade em Rede-Unirede, 2011.

UNIVESP. UNIVESP. Plano de Desenvolvimento Institucional-PDI 2018-2022. Disponível em: https://XXXX. br/sites/58f6506869226e9479d38201/assets/5d5d93c27c1bd15a5a1803cd/PDI_XXXX_2018_2022.pdf Acesso em: 20 jan. 2021

TORRES, E. F.; MAZZONI, A. A.; MELLO, A. G. de. Nem toda pessoa cega lê em Braille, nem toda pessoa surda se comunica em língua de sinais. Educação e Pesquisa, São Paulo, v.33, n.2, p. 369-385, maio/ago. 2007. Disponível em: https://www.scielo.br/j/ep/a/DmVQcky9hfRjBHzdYcjmLJw/?format=pdf\&lang=pt Acesso em: 22 dez. 2021. 